\title{
Predictive Modeling of Oxygen Transmission Through Micro-perforations for Packaging Applications
}

\author{
Ayman Abdellatief \\ University of Florida \\ ayman@ufl.edu \\ Jason Butler \\ University of Florida \\ butler@che.ufl.edu \\ Arthur Teixeira \\ University of Florida \\ atex@ufl.edu
}

\author{
Bruce A. Welt \\ University of Florida \\ bwelt@ufl.edu \\ Eric McLamore \\ University of Florida \\ emclamor@ufl.edu
}

Sanjay Shukla

University of Florida

Sanjay Shukla

\begin{abstract}
Methods for creating precise perforations in respiring produce packaging are being increasingly adopted. Knowledge of oxygen transfer through perforated packaging and oxygen distribution in packages is necessary for successful packaging design of fresh produce. An approach to modeling perforated packaging performance was developed using a cylindrical chamber with precision perforations using Fick's second law. The model was simulated using two techniques including Finite Element Method (FEM) using commercially available software and Finite Volume Method (FVM) through programming. Perforations were approximated as a source term in the second method. Both simulation techniques showed trends similar to experimental data.
\end{abstract}

Key Words: permeation, modified atmosphere packaging, MAP, oxygen transmission rate, perforation, microperforation

NOMENCLATURE

C Concentration of gas $\left(\right.$ moles $\left./ \mathrm{m}^{3}\right)$

t time (s)

D Diffusion Coefficient $\left(\mathrm{m}^{2} / \mathrm{s}\right)$

$\mathrm{r} \quad$ radial distance from center $(\mathrm{m})$

$\mathrm{R}$ total radius of chamber (m) $\mathrm{z} \quad$ axial distance from top (m)

$\mathrm{L}$ total length of chamber (m)

$\mathrm{S} \quad$ source term to deliver oxygen into the chamber $\left(\mathrm{mole} / \mathrm{m}^{3} / \mathrm{s}\right)$

$\ell \quad$ thickness of perforation (m) 
$\ell_{\text {effective }}$ effective diffusive path length of oxygen through chamber $(\mathrm{m})$

$\mathrm{d}$ diameter of perforation $(\mathrm{m})$

$\mathrm{N}_{\mathrm{r}} \quad$ number of nodes in radial direction

$\mathrm{N}_{2} \quad$ number of nodes in axial direction

$A_{\text {perforation }}$ Area of Transmission normal to gas flow through perforation $\left(\mathrm{m}^{2}\right)$

$\mathrm{C}_{\text {Ambient }} \mathrm{O}_{2}$ in ambient atmosphere $\left(\mathrm{mole} / \mathrm{m}^{3}\right)$

$\mathrm{C}_{\mathrm{i}, \mathrm{j}}^{\mathrm{t}} \quad \mathrm{O}_{2}$ at a specific time and position inside the accumulation chamber (mole $/ \mathrm{m}^{3}$ )

$\mathrm{a}_{\mathrm{in}_{\mathrm{i}}} \quad$ Coefficientassociated with oxygen transfer from inside (dimensionless)

$\mathrm{a}_{\text {out }_{\mathrm{i}}}$ Coefficient associated with oxygen transfer from outside (dimensionless)

$a_{p} \quad$ Coefficient associated with a particular control volume (dimensionless)

$\mathrm{a}_{\mathrm{up}_{\mathrm{j}}} \quad$ Coefficient associated with oxygen transfer from above (dimensionless)

$\mathrm{a}_{\text {down }_{\mathrm{j}}}$ Coefficient associated with oxygen

\subsection{INTRODUCTION}

Perforating films is a method used in the design of packaging of fresh or minimally processed fruits and vegetables [1-8]. Modified atmosphere packaging (MAP) is commonly used to extend product shelf life of minimally processed produce. MAP works by reducing rates of overall aerobic metabolic activity, which reduces consumption rate of $\mathrm{O}_{2}$ and production rate of $\mathrm{CO}_{2}$ [9-15]. Unfortunately, many respiring products have oxygen requirements that exceed what can be supplied by even the highest oxygen permeating packaging films or films with other desirable characteristics such as puncture resistance, freezerto-microwave capability, etc. don't offer adequate gas transmission properties. Therefore, it becomes necessary to incorporate perforations in packaging to meet gas exchange requirements. Incorporating even small perforations in packaging material can drastically increase gas transmission, because transfer from below (dimensionless)

$b_{i, j} \quad$ constant, right side of algebraic equation for a particular control volume (moles)

f time step weight coefficient (dimensionless)

$\mathrm{n}_{\mathrm{i}, \mathrm{j}} \quad$ number of moles of oxygen in a control volume (moles)

$r_{i} \quad$ radial position in accumulation chamber with perforation

$\mathrm{r}_{\mathrm{in}_{\mathrm{i}}} \quad$ inside radial boundary of a control volume

$\mathrm{r}_{\text {out }_{i}} \quad$ outside radial boundary of a control volume

$r_{\text {perforation }}$ radius of perforation

$\mathrm{V}_{\mathrm{i}, \mathrm{j}}$ Volume of a control volume in accumulation chamber with perforation

$\mathrm{Z}_{\text {down }}$ bottom axial boundary of a control volume

$\mathrm{z}_{\mathrm{j}} \quad$ axial position in accumulation chamber with perforation

$\mathrm{z}_{\mathrm{up}_{\mathrm{j}}} \quad$ top axial boundary of a control volume time step (s)

diffusion coefficients of permeant gasses in air are at least 6 orders of magnitude greater than their permeability in high gas transmitting low density polyethylene (LDPE) [5]. The most common gas transmissions through a perforation modeled in a modified atmosphere package are $\mathrm{O}_{2}$ and $\mathrm{CO}_{2}$ but other volatile compounds produced from the metabolic activity of fresh fruits and vegetables also have a significant effect on shelf life [16].

Many attempts to model oxygen transmission through perforations have been reported with various degrees of success for broad application. Several researchers modeled the oxygen transmission through perforations empirically [6, 8, 17 - 18] but these approaches have limited applicability [19 - 20]. Approaches based on theoretical principles of Fick's Law have been applied by a number of studies $[1,5,21]$. Other theoretical models have been developed. Renault et al. modeled gas diffusion from the ambient environment through 
perforations using Stephen-Maxwell gas laws and inside the package using Fick's law [22]. Hirata et al. used Graham's law of Effusion for designing a modified atmosphere package with a perforation [23]. Del-Valle et al. modeled gas exchange through perforations by applying Knudsen gas diffusivities and Poiseuille's hydrodynamic flow [24].

Most studies assume that the concentration inside of a perforated package is uniform at any particular time. However when oxygen transmits very rapidly in small localized areas compared to the rest of the package, oxygen concentrations tend to not be uniform. To address this issue, oxygen concentrations may be predicted throughout the package rather than assuming uniformity. Rennie and Tavoularis (2009) modeled a time and space dependent modified atmosphere package using Finite Element Method [25]. Emond et al. discretized a modified atmosphere package using the finite difference method [26]

Two experimental methods are mentioned in the literature to measure oxygen transmission through perforations; the flow through method and the static method. In the flow through method the apparatus is setup as described in ASTM D 3985 [27-29] Figure 1. The main problem with the flow through method for measuring oxygen transmission through perforations is the difficulty in maintaining the same pressure on both sides of the sample. Even slight differences in pressure will cause convective flow through the perforation leading to inaccurate measurements.

In the static method, a chamber is sealed with a perforated sample and flushed with an inert gas, typically nitrogen (Figure 2). After purging,

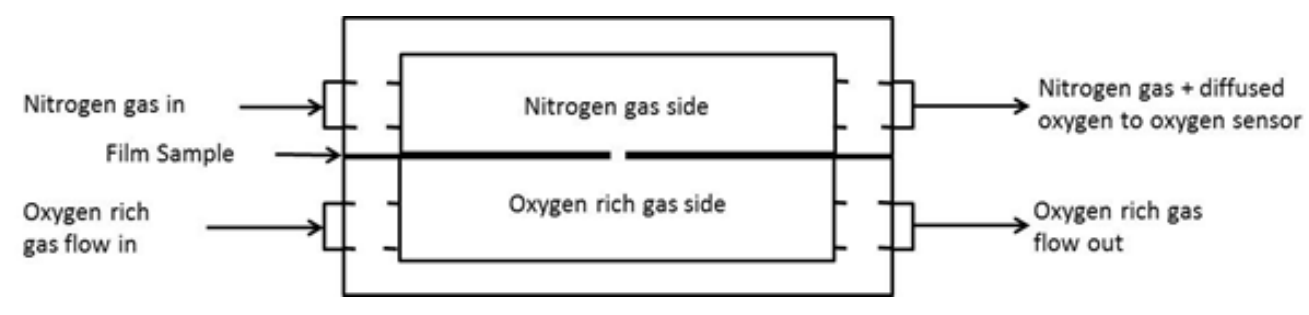

Figure 1 Schematic representation of the flow through method for measuring oxygen transmission through a perforated film.

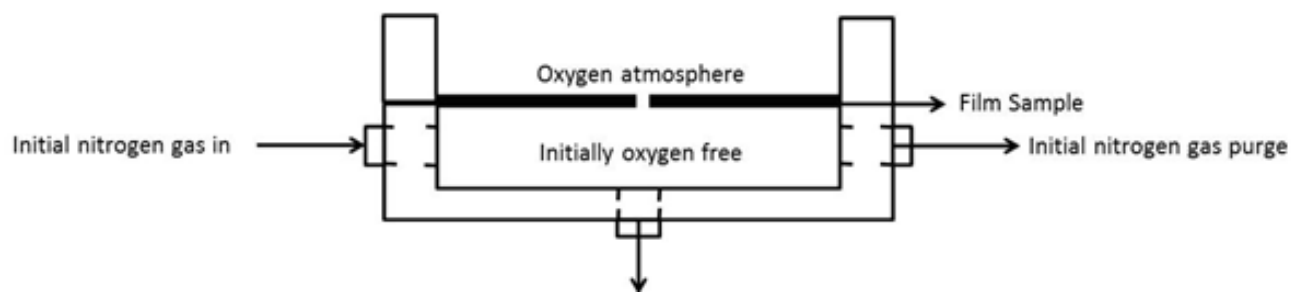

Figure 2 Schematic representation of the static method for measuring oxygen transmission through a perforated film. 
accumulation of oxygen in the chamber is measured over time. There are some limitations to the static method, namely, samples have to be small and few otherwise the oxygen concentration in the chamber and accuracy will be significantly affected [30], or the chamber has to be re-purged after withdrawing each sample resulting in exceedingly long test times [28]. These limitations can be overcome by using a non-invasive and nondestructive oxygen measuring system such as a fluorescence based oxygen sensor [31]. Fluorescent oxygen sensing enables measurement of oxygen concentration without withdrawing samples from the accumulation chamber and affecting accuracy.

\subsection{MATERIALS AND METHODS}

In this study the static method was used with a fluorescence based oxygen sensing system (Model 310, Oxysense, Inc. Dallas, TX). A chamber 7.125 inches in length was constructed from schedule 40 PVC pipe. At the center of one end of the chamber a perforated disc was mounted and at the center of the other end, oxygen was measured (Figure 3).

To measure oxygen transmission, the chamber was kept at room temperature $\left(23^{\circ} \mathrm{C}\right)$ and purged with nitrogen and initially contained no oxygen.
Oxygen was allowed to accumulate in the chamber and oxygen concentration was measured at the sensor approximately every 15 minutes until concentration at the sensor exceeded 5\%. Oxygen transmission through 3 different sized precision perforations was measured. The perforations consisted of stainless steel disks that measured 0.003 inches thick with precision orifices 100 , 205, $249 \mu \mathrm{m}$, respectively (Lenox Laser, Glen Arm, MD). Tests were done in triplicate and experimental data were compared with predictions from a model simulated using two techniques. One technique was derived with commercial software (COMSOL Multiphysics, Stockholm, Sweden). COMSOL discretized a 2D model of half of the experimental apparatus with the center of the precision orifice as the origin into triangular meshes (Figure $4 \mathrm{a}$ ) and then predicted oxygen mass transfer (in moles) using the Finite Element Method. Meshing was set on 'extra fine' setting. The results of the simulation were revolved around a horizontal axis passing through the center of the perforation to give $3 \mathrm{D}$ results with a significantly reduced computational effort. The second technique was written in Visual Basic for Applications (Microsoft Inc., Redmond, WA) and derived by discretizing the accumulation chamber into concentric toroids surrounding central

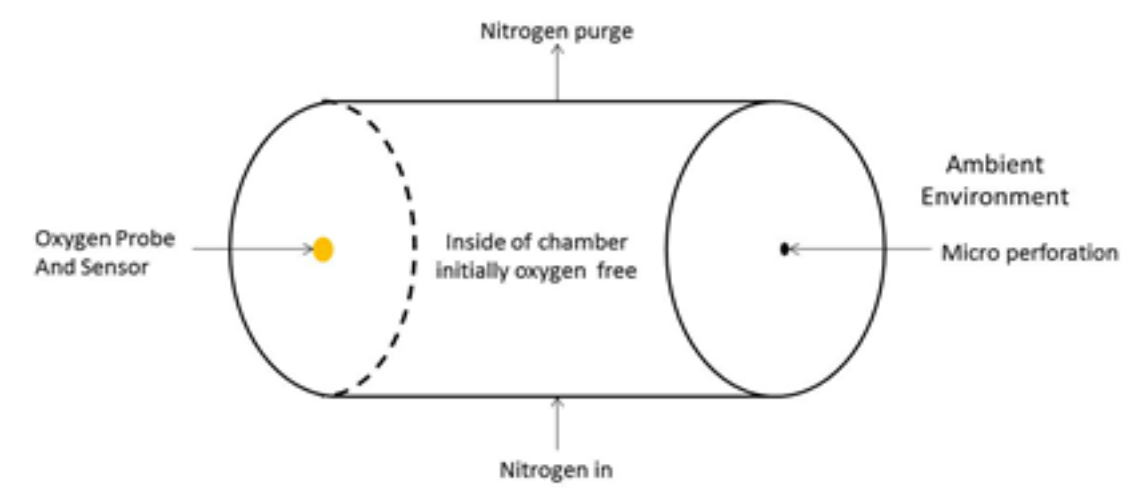

Figure 3 Schematic representation of the static method for measuring oxygen transmission through a perforated film. 


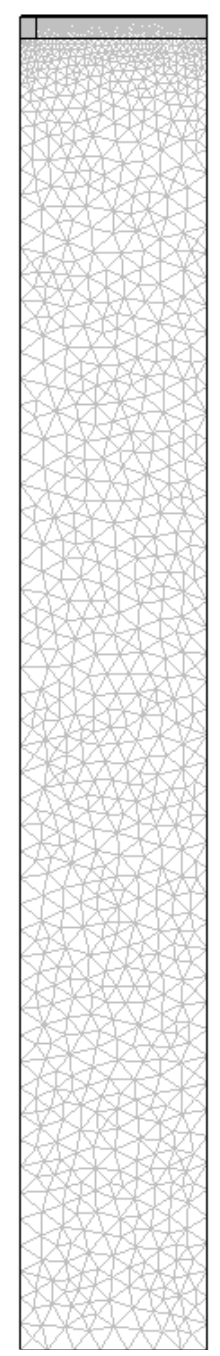

Figure 4 a Schematic representation of the static method for measuring oxygen transmission through a perforated film.

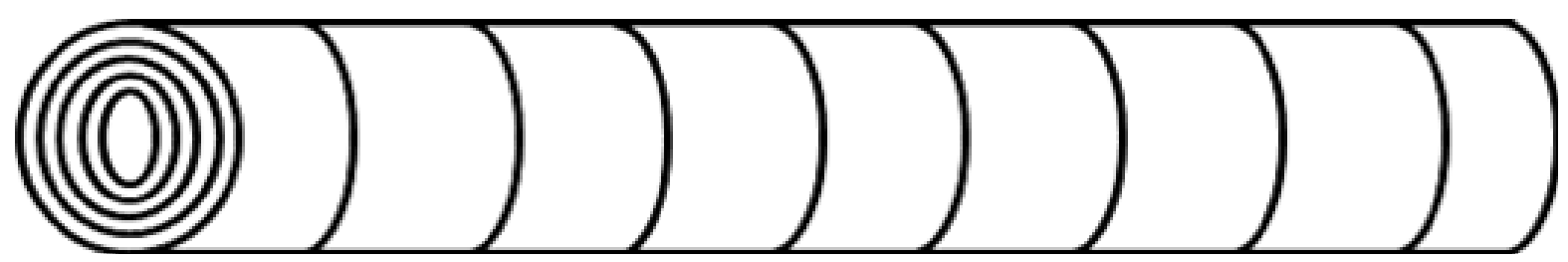

Figure $4 b$ Schematic representation of the static method for measuring oxygen transmission through a perforated film. 
cylindrical discs with constant $\Delta \mathrm{r}$ stacked on top of each other with constant $\Delta z$ (Figure $4 \mathrm{~b}$ ) and then predicted oxygen mass transfer (in moles) using either Finite Volume or Finite Difference methods. Oxygen transmission through the precision orifice was approximated as a source term whereas COMSOL discretized the perforation directly. By approximating a perforation as a source term the number of elements or control volumes, calculations, and run time is considerably reduced.

\subsection{THEORY AND CALCULATION}

\subsection{THE MODEL}

As a result of the perforation being centered on the end of the chamber the model can be considered 2D axial symmetric with oxygen transfer in the radial and axial directions (Figure 5).

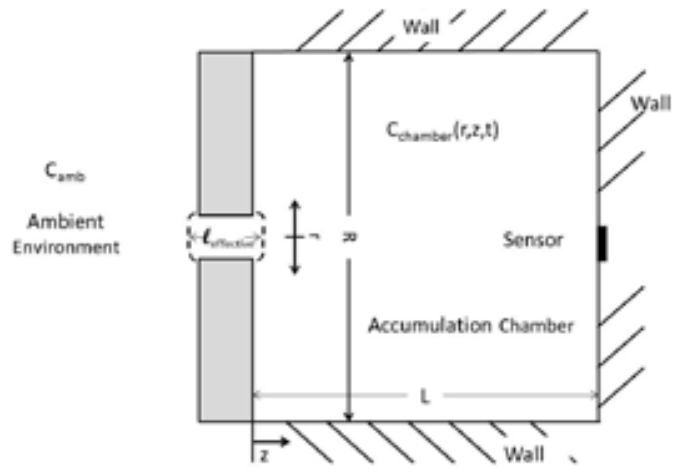

Figure 5 Schematic Profile of Oxygen Accumulation Chamber with centered perforation.

The governing differential equation for oxygen transfer in the accumulation chamber can be derived from Fick's second law in cylindrical coordinates and is given in equation 1 [32]. Oxygen delivered from the ambient environment to the accumulation chamber through the perforation is approximated as a source term (Equation 1)

$$
\frac{\partial \mathrm{C}}{\partial \mathrm{t}}=\mathrm{D} \frac{1}{\mathrm{r}} \frac{\partial}{\partial \mathrm{r}}\left(\mathrm{r} \frac{\partial \mathrm{C}}{\partial \mathrm{r}}\right)+\mathrm{D} \frac{\partial^{2} \mathrm{C}}{\partial \mathrm{z}^{2}}+\mathrm{S}
$$

With the following initial and boundary conditions (Equations 2-5). Initially there is no oxygen (Equation 2)

$$
\mathrm{C}(\mathrm{r}, \mathrm{z}, \mathrm{t}=0)=0 \text {; For all } \mathrm{r} \text { and } \mathrm{z} \text { at } \mathrm{t}=0
$$

Oxygen cannot transfer in through the center (Equation 3).

$$
\left.\frac{\partial \mathrm{C}}{\partial \mathrm{r}}\right|_{\mathrm{r}=0}=0
$$

Oxygen cannot transfer out through the wall (Equation 4).

$$
\left.\frac{\partial \mathrm{C}}{\partial \mathrm{r}}\right|_{\mathrm{r}=\mathrm{R}}=0
$$

Oxygen cannot transfer up through the top (Equation 5).

$$
\left.\frac{\partial \mathrm{C}}{\partial \mathrm{z}}\right|_{\mathrm{z}=0}=0
$$

Oxygen cannot transfer down through the bottom (Equation 6).

$$
\left.\frac{\partial \mathrm{C}}{\partial \mathrm{z}}\right|_{\mathrm{z}=\mathrm{L}}=0
$$

Several studies demonstrated an improvement in mass transfer predictions through perforations by considering edge effects via a modified effective diffusion length $[1,3,5]$. Justification for the corrective term is rooted in local gas density differences as a consequence of end effects of the perforation. This effect is significant for the diameters and thicknesses of typical micro perforated films used in MAP. The effective diffusion path length for a narrow tube that resembles stomata in plants is given by Equation 
7 [33]. Equation 7 is derived by the resistance to diffusion at ends of the perforation and through the perforation itself and was used here. (Equation 7)

$$
\ell_{\text {effective }}=\ell+\frac{\pi \mathrm{d}}{4}
$$

\subsection{NUMERICAL SOLUTION OF MODEL}

The solution to Equation 1 was approximated numerically by discretizing the accumulation chamber into cylindrical discs in the center and toroids everywhere else (Figure 4b). Oxygen transferred into the accumulation chamber is approximated as a source term and is delivered into the top center disc at each time step (Equation 8).

$$
\mathrm{S}=\frac{\mathrm{DA}_{\text {perforation }}}{\ell_{\text {effective }}}\left(\mathrm{C}_{\text {Ambient }}-\mathrm{C}_{1,1}^{\mathrm{t}}\right) \Delta \mathrm{t}
$$

Oxygen is transferred to the adjacent positions by integrating the governing differential equation over the subdomain of each position, known as the Finite Volume Method (Equation 9).
The other approach would be to perform mass balances at each surface of each position. Both procedures yield the same algebraic equation. (Equation 10)

Where the coefficients $\mathrm{a}_{\text {in }}, \mathrm{a}_{\text {out }}, \mathrm{a}_{\mathrm{p}}, \mathrm{a}_{\text {up }}$, and $\mathrm{a}_{\text {down }}$ depend on position, diffusion coefficient and size of the time step. As a result of toroids and discs in the discretized system varying in size it is useful to convert the algebraic equations in terms of moles (Equation 11) which ensures conservation of mass.

Since the volumes are known, Equation 11 can be rearranged so that the left side is in terms of moles of each position and corresponding adjacent position for the next time step with the corresponding coefficients. The volumes are incorporated into the right side of the equation, $b_{i, j}$, along with all the other corresponding known values. (Equation 12)

Constant $\mathrm{f}$ is typically set to 0,1 , or 0.5 and gives the weight of the current time step to the next time step. If $\mathrm{f}=0$ then the oxygen concentration

$$
\int_{z_{\text {up }}}^{z_{\text {down }}} \int_{r_{\text {in }}}^{r_{\text {out }}} \int_{t}^{t+\Delta t} \frac{\partial C}{\partial t} r d r d z=\int_{t}^{t+\Delta t} \int_{z_{\text {up }}}^{z_{\text {down }}} \int_{r_{\text {in }}}^{r_{\text {out }}} \mathrm{D} \frac{1}{r} \frac{\partial}{\partial r}\left(r \frac{\partial C}{\partial r}\right) r d r d z+\int_{t}^{t+\Delta t} \int_{r_{\text {in }}}^{r_{\text {out }}} \int_{z_{\text {up }}}^{z_{\text {down }}}\left(\frac{\partial^{2} \mathrm{C}}{\partial z^{2}}\right) r d r d z
$$

Equation 9

$$
a_{i n_{i}} f_{i-1, j}^{t+\Delta t}+a_{\text {out }_{i}} f_{i+1, j}^{t+\Delta t}+a_{p_{i, j}} f_{i, j}^{t+\Delta t}+a_{u p_{j}} f_{i, j-1}^{t+\Delta t}+a_{\text {down }_{j}} f_{i, j+1}^{t+\Delta t}=b_{i, j}
$$

Equation 10

$$
a_{i n_{i}} f \frac{n_{i-1, j}^{t+\Delta t}}{V_{i-1, j}}+a_{\text {out }_{i}} f \frac{n_{i+1, j}^{t+\Delta t}}{V_{i+1, j}}+a_{p_{i, j}} f \frac{n_{i, j}^{t+\Delta t}}{V_{i, j}}+a_{u_{j}} f \frac{n_{i, j-1}^{t+\Delta t}}{V_{i, j-1}}+a_{d o w n} f \frac{n_{i, j+1}^{t+\Delta t}}{V_{i, j+1}}=b_{i, j}
$$

\section{Equation 11}

$$
a_{i n_{i}} f n_{i-1, j}^{t+\Delta t}+a_{\text {out }_{i}} f_{i+1, j}^{t+\Delta t}+a_{p_{i, j}} f n_{i, j}^{t+\Delta t}+a_{u p_{j}} f_{i, j-1}^{t+\Delta t}+a_{d o w n} f_{i, j+1}^{t+\Delta t}=b_{i, j}
$$

\section{Equation 12}


at a particular position is only dependent on the oxygen concentration of the position and adjacent positions at the current time step and the equation becomes fully explicit. The advantage of an explicit scheme is that it is simpler and does not require a solution of simultaneous equations; however, it is less accurate for a particular time step than other schemes and requires a smaller time step to be numerically stable. If $\mathrm{f}=1$ then the oxygen concentration at a particular position is only dependent on the oxygen concentration of the position and adjacent positions at the next time step and the equation becomes fully implicit. The advantage of a fully implicit scheme is that it allows a larger time step and is more accurate than an explicit scheme for a particular time step at the expense of having to solve simultaneous equations. If $\mathrm{f}=0.5$ then the oxygen concentration at a particular position is equally dependent on the oxygen concentration of the position and adjacent positions at the current time step and next time step. This scheme is known as the Crank-Nicolson scheme and also allows for larger time step but also requires a solution of simultaneous equations. It is considered the most accurate of the 3 schemes for a particular time step size [34] and is used in this study.

Right side of equation $12, b_{i, j}$, is a function of the constant $f$, constants $a_{\text {in }}, a_{\text {out }}, a_{p}, a_{\text {up }}$, and $a_{\text {down }}$, and the current moles of oxygen at the position and adjacent positions and the ratio of their volumes to the volume of the position.

Equation 12 has 5 unknowns which gives a sparse matrix of dimension $\left(\mathrm{Nr}^{2} \mathrm{xNz}^{2}\right)$ when all positions are solved simultaneously. Where $\mathrm{Nr}$ is the number of positions in the radial dimension and $\mathrm{Nz}$ is the number of positions in the axial dimension. When solving this $\left(\mathrm{Nr}^{2} \mathrm{xNz}^{2}\right)$ matrix with a direct method like Gaussian elimination, it requires on the order of $\left(\mathrm{Nr}^{2} \mathrm{xNz}^{2}\right)^{3}$ operations for each time step. For Parabolic Partial Differential Equations dependent on time and space, the time step can be split by the number of spatial dimensions ( 2 in this case) and each spatial dimension can be solved separately but sequentially. This reduces the sparse matrix into a series of tridiagonal matrices (Equations 13 and 14), one for each dimension. Results from solving one dimension are substituted into the next dimension in order to cancel out the bias in each dimension. This method is known as the Alternating Direction Implicit Scheme and reduces the order of operations in this problem from $\left(\mathrm{Nr}^{2} \mathrm{xNz}^{2}\right)^{3}$ with a direct elimination method to $\left(2 \mathrm{xNr}^{2} \mathrm{xNz}^{2}\right)$. The axial half of equation 12 is (Equation 13)

$$
\frac{1}{2}\left(\mathrm{a}_{\mathrm{up}_{\mathrm{j}}} \mathrm{fn}_{\mathrm{i}, \mathrm{j}-1}^{\mathrm{t}+\Delta \mathrm{t}}+\mathrm{a}_{\mathrm{p}_{\mathrm{j}}} \mathrm{fn}_{\mathrm{i}, \mathrm{j}}^{\mathrm{t}+\Delta \mathrm{t}}+\mathrm{a}_{\mathrm{down}} \mathrm{fn}_{\mathrm{i}, \mathrm{j}+1}^{\mathrm{t}+\Delta \mathrm{t}}\right)=\mathrm{b}_{\mathrm{i}, \mathrm{j}}
$$

Oxygen predicted for each position in Equation 13 can be substituted into radial half of the time step. (Equation 14)

$$
\frac{1}{2}\left(a_{i n_{i}} f_{i-1, j}^{t+\Delta t}+a_{p_{i}} f n_{i, j}^{t+\Delta t}+a_{\text {out }_{i}} f_{i, j+1}^{t+\Delta t}\right)=b_{i, j}
$$

There are three different types of positions for both axial and radial dimensions. In the axial dimensions there is the top, interior (between top and bottom), and bottom positions, with corresponding coefficients $a_{u p}, a_{\text {down }}, a_{p}$, (Table 1a1) and right side of Equation 13, $b_{i, j}$, (Table 1a-2). In the radial dimension there is the top, interior (between top and bottom), and bottom positions, with corresponding coefficients $a_{\text {in }}, a_{\text {out }}, a_{p}$, (Table 1b-1) and right side Equation 14, $\mathrm{b}_{\mathrm{i}, \mathrm{j}}$, (Table 1b-2). 


\begin{tabular}{|c|c|c|c|}
\hline & Top & Interior & Bottom \\
\hline \multirow[b]{2}{*}{$0_{4}$} & \multirow[b]{2}{*}{0} & $\mathrm{D} \Delta t$ & $\mathrm{D} \Delta \mathrm{t}$ \\
\hline & & $\overline{\left(z_{\text {dem }}-z_{\text {atson }, i}\right)\left(z_{j}-z_{j a}\right)}$ & $\overline{\left(L-z_{\text {timat }}\right)\left(L-z_{\text {siti }}\right)}$ \\
\hline & Dst & $\mathrm{D} \Delta \mathrm{t}$ & \\
\hline$a_{\text {osen }}$ & $\overline{z_{y_{m}, p_{1}}\left(z,-z_{1}\right)}$ & 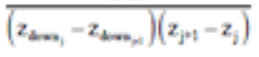 & 0 \\
\hline$a_{p}$ & $\left(1+a_{\theta e m}\right)$ & $-\left(1+a_{a p}+a_{60 m a n}\right)$ & $-(1+2, a)$ \\
\hline
\end{tabular}

Table 1a-1 Coefficients aup, adown, and, ap in the axial direction. through a perforated film.

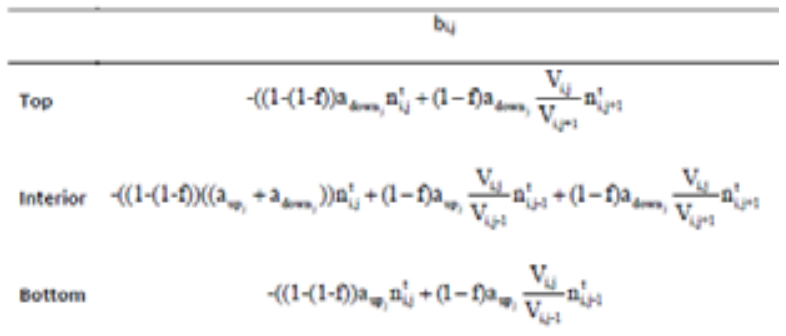

Table 1a-2 Right side of equation 12, bi,j, in axial direction.

\begin{tabular}{|c|c|c|c|}
\hline & Center & Interior & Wall \\
\hline \multirow[b]{2}{*}{$a_{\text {in }}$} & \multirow[b]{2}{*}{0} & $2 \mathrm{r}_{\text {out }-1} \mathrm{D} \Delta \mathrm{t}$ & $2 \mathrm{r}_{\text {out }} \mathrm{D} \Delta \mathrm{t}$ \\
\hline & & 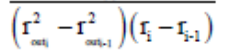 & $\overline{\left(R^{2}-r^{2}\right)\left(R-r_{N r-1}\right)}$ \\
\hline \multirow[b]{2}{*}{$a_{\text {out }}$} & $2 \mathrm{D} \Delta \mathrm{t}$ & $2 \mathrm{r}_{\text {out }} \mathrm{D} \Delta \mathrm{t}$ & \multirow[b]{2}{*}{0} \\
\hline & $\overline{\mathrm{r}_{\mathrm{outr}_{1}}\left(\mathrm{r}_{2}-\mathrm{r}_{1}\right)}$ & 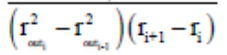 & \\
\hline$a_{p}$ & $-\left(1+a_{o u t}\right)$ & $-\left(1+a_{\text {in }}+a_{\text {out }}\right)$ & $-\left(1+a_{\text {in }}\right)$ \\
\hline
\end{tabular}

Table 1b-1 Coefficients ain, aout, and, ap in the radial direction.

\begin{tabular}{|c|c|}
\hline & $\mathbf{b}_{\mathrm{ij}}$ \\
\hline Center & $-\left((1-(1-f)) a_{\text {out }} n_{i, j}^{t}+(1-f) a_{o w n} \frac{V_{i, j}}{V_{i+1, j}} n_{i+1, j}^{t}\right.$ \\
\hline Interior & $-\left((1-(1-f))\left(\left(a_{i i_{i}}+a_{\text {out }}\right)\right) n_{i, j}^{t}+(1-f) a_{i i_{i}} \frac{V_{i j,}}{V_{i-1, j}} n_{i-1, j}^{t}+(1-f) a_{\text {outi }} \frac{V_{i j}}{V_{i+1, j}} n_{i+1, j}^{t}\right.$ \\
\hline Wall & $-\left((1-(1-f)) a_{i, i} n_{i, j}^{t}+(1-f) a_{i, i} \frac{V_{i, j}}{V_{i-1, j}} n_{i-1, j}^{t}\right.$ \\
\hline
\end{tabular}

Table 1b-2 Right side of equation 12, bi,j, in radial direction.

\subsection{SIMULATION OF THE MODEL}

\subsubsection{COMPUTATION TIME MINIMIZATION STRATEGIES}

Right hand side, $b_{i, j}$, of Equations $13 \& 14$ and coefficient $a_{p}$ must have the opposite sign from coefficients $\mathrm{a}_{\text {in }}, \mathrm{a}_{\text {out }}, \mathrm{a}_{\text {up }}$, and $\mathrm{a}_{\text {down }}$ for the simulation to be numerically stable. When $\Delta \mathrm{t}$ becomes too large these criteria are not met and the simulation becomes unstable. As the simulation progresses and the oxygen concentration increases at all positions in the chamber a larger $\Delta \mathrm{t}$ can be afforded. This criterion can be used to find the maximum possible $\Delta \mathrm{t}$ at each time step within a margin of safety rather than arbitrarily setting a constant $\Delta \mathrm{t}$ throughout the simulation. An algorithm was developed where $\Delta \mathrm{t}$ was increased incrementally by $1 \%$ until the criterion were not met. Then $\Delta t$ was decreased by $1 \%$ so it meets the criteria again and is within $1 \%$ of the maximum possible value.

\subsubsection{SIMULATION CONVERGENCE VERSUS COMPUTATIONAL COST}

Improved accuracy can be obtained with finer discretization, but at the cost of computation time. By doubling the number of discretized positions in each dimension the computation time can increase by as much as a factor of 200 per simulation. To mitigate this problem, we developed a dynamic discretization scheme that starts fine and becomes increasingly coarse as gas concentrations tend to become similar in growing regions. In this study, there is a limit to how fine the accumulation chamber can be discretized, since oxygen transmission through the perforation is approximated as a source term, the top center control volume can be no smaller than the size of the perforation itself. It was found that when the number of positions exceeded a ratio of the 


\begin{tabular}{lc}
\hline Parameter or Dimension & Value \\
\hline Length of Chamber (L) & $18.0975 \mathrm{~cm}$ \\
Average Radius of Chamber (R) & $2.56137 \mathrm{~cm}$ \\
Ambient $\mathrm{O}_{2}$ Concentration at $23^{\circ} \mathrm{C}$ & $8.60 \times 10^{-6} \mathrm{~mol} / \mathrm{cm}^{3}$ \\
Diffusion Coefficient of $\mathrm{O}_{2}$ in air at $23^{\circ} \mathrm{C}^{\circ}$ & $0.204911638 \mathrm{~cm}^{2} / \mathrm{s}$ \\
\hline
\end{tabular}

Table 2 Dimensions and parameters inputted into the model. * [35]

\begin{tabular}{lccc}
\hline Precision & Perforation & Effective & Simulated \\
Orifice & Radius & Diffusion Length & Time \\
\hline $249 \mu \mathrm{m}$ & $0.0124475 \mathrm{~cm}$ & $0.027125 \mathrm{~cm}$ & $9.17 \mathrm{~h}$ \\
$205 \mu \mathrm{m}$ & $0.0102445 \mathrm{~cm}$ & $0.023712 \mathrm{~cm}$ & $10.00 \mathrm{~h}$ \\
$100 \mu \mathrm{m}$ & $0.0050065 \mathrm{~cm}$ & $0.015484 \mathrm{~cm}$ & $24.44 \mathrm{~h}$ \\
\hline
\end{tabular}

Table 3 a Perforation radius, effective diffusion length, and simulated times (approximate time it took experiment to reach $5 \% \mathrm{O}_{2}$ ) was inputted into COMSOL and VBA models for each precision orifice.

\begin{tabular}{lcc}
\hline \multirow{2}{*}{ Precision } & \multicolumn{2}{c}{ VBA Model } \\
Orifice & Initial Discretization & Final Discretization \\
& $137 \times 479$ & (NrxNz) \\
\hline $249 \mu \mathrm{m}$ & $166 \times 581$ & $8 \times 29$ \\
$205 \mu \mathrm{m}$ & $341 \times 1193$ & $10 \times 36$ \\
$100 \mu \mathrm{m}$ & & $10 \times 37$ \\
\hline
\end{tabular}

Table $3 b$ Initial and Final Discretization used in COMSOL and VBA models for each precision orifice

average radius of the chamber to $1 \frac{1 / 2}{2}$ times the radius of the perforation in the radial dimension, the concentration in the top center node exceeded ambient concentration, which is physically impossible. In this study, the radial dimension of the accumulation chamber was discretized to the nearest integer less than the ratio just described. The axial dimension was discretized to the nearest integer less than $31 / 2$ times the number of radial positions for an aspect ratio close to unity. When oxygen concentrations ceased to increase by at least $1 \%$ throughout the chamber, the number of discretized positions was reduced by half in both axial and radial dimensions. Naturally, mass was preserved by combining oxygen from joined volumes. This procedure was repeated until the number of nodes in the radial dimension was less than or equal to 10 which gave a very reasonable time step size. This novel dynamic discretization approach has not been described previously.

\subsubsection{VALUES OF DIMENSIONS AND PARAMETERS ENTERED INTO THE MODEL AND DISCRETIZATION OF ACCUMULATION CHAMBER}

Values of dimensions of the accumulation chamber and parameters entered into COMSOL and VBA program are given in Table 2. COMSOL was run on extra fine meshing setting. Perforation radius, effective diffusion length, and simulated time (approximate amount of time experiment was run) entered into COMSOL and VBA program for each precision orifice are given in Table 3a. Initial discretization and final discretization entered used in VBA program for each precision orifice are given in Table $3 b$.

\subsection{RESULTS AND DISCUSSION}

Table 4 compares final oxygen concentration at the sensor location achieved by running an experiment and simulating COMSOL and VBA models for each orifice for the times shown in Table 3.

Figures 6a-c compares the curve $\% \mathrm{O}_{2}$ at sensor versus time generated from experimental data 


\begin{tabular}{lccc}
\hline Precision Orifice & Experimental Value & Value Predicted by & Value Predicted by \\
& & Comsol Model & VBA Model \\
\hline $249 \mu \mathrm{m}$ & $5.17 \%$ & $4.89 \%$ & $5.19 \%$ \\
$205 \mu \mathrm{m}$ & $5.08 \%$ & $4.69 \%$ & $4.46 \%$ \\
$100 \mu \mathrm{m}$ & $5.03 \%$ & $4.57 \%$ & $4.09 \%$ \\
\hline
\end{tabular}

Table 4 Final \%O2 at sensor location achieved by running an experiment and simulating the same amount of time the experiment was run for both COMSOL and VBA models for each orifice as shown in Table 3.

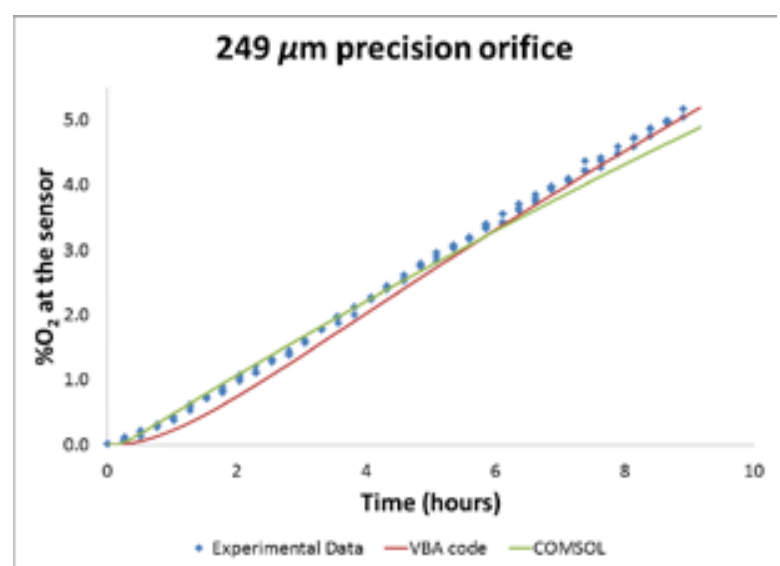

Figure 6a Curve of Oxygen Concentration at Sensor versus time generated by experimental data, COMSOL, and VBA code for $249 \mu \mathrm{m}$ precision orifice mounted on accumulation chamber.

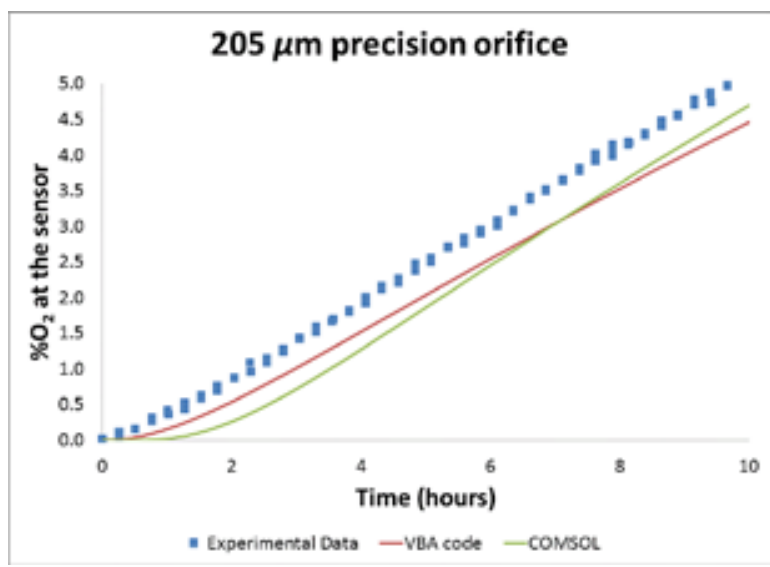

Figure $6 b$ Curve of Oxygen Concentration at

Sensor versus time generated by experimental data, COMSOL, and VBA code for $205 \mu \mathrm{m}$ precision orifice mounted on accumulation chamber.

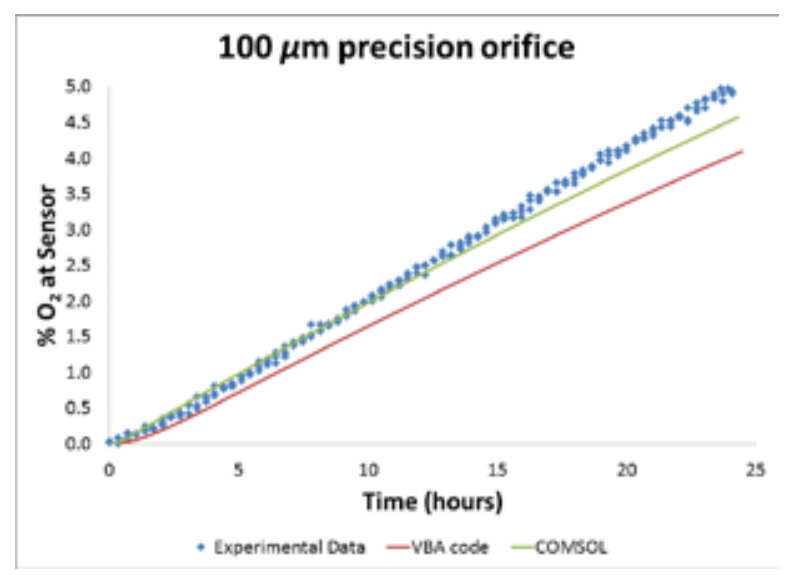

Figure 6c Curve of Oxygen Concentration at Sensor versus time generated by experimental data, COMSOL, and VBA model for $100 \mu \mathrm{m}$ precision orifice mounted on accumulation chamber.

to the curve generated by COMSOL and VBA models for each orifice.

Table 4 and Figures 6a-c demonstrates model predictions of oxygen concentration at the accumulation chamber sensor can serve as a reasonable approximation with both methods when compared to experimentally measured values. The model becomes slightly more accurate when the perforation is discretized. Approximating oxygen transmitted from the perforation as a source term can still serve as a reasonable simplification and does not require expensive commercial software. 
In this work the perforations were made in the metal disk by a laser. Laser perforated materials more closely resemble a smooth circle when seen under a microscope whereas mechanically perforated materials are irregular in shape and have jagged edges. It is expected that using a circle of the same area as the mechanical perforation would be a sufficient approximation in determining the OTR of a mechanically perforated material considering the area of the perforation is several orders of magnitude smaller than the area of the package itself. This hypothesis of the effect of microperforation geometry on the OTR of a package can be tested using multiphysics software like COMSOL.

\subsection{CONCLUSIONS}

Oxygen transmission through a microperforation into a package can be modeled using Fick's $2^{\text {nd }}$ law. Accurate predictions required use of an effective diffusion length through the perforation that is longer than the thickness of the perforation. Estimating oxygen diffusion through a micro-perforation as a source term gave a reasonable approximation of oxygen concentration at the sensor when applied in the VBA model. Discretization of the perforation gave more precise results as demonstrated by the COMSOL model, but at the expense of complexity and cost. As diameter for the perforation decreased, the discrepancy between the experimental data and the prediction by both models increased. This could be due to due to discrepancy between the theoretically derived effective diffusion path length and actual effective diffusion path length that increases as the perforation diameter decreases.

\section{Acknowledgements}

This work was funded in part by Oxysense, Inc., Dallas TX and the Florida Agricultural Experiment Station. 


\section{REFERENCES}

[1] Fishman, S., Rodov, V., \& Ben Yehoshua, S. (1996, September - October). Mathematical Model for Perforation Effect on Oxygen and Water Vapor Dynamics in Modified Atmosphere Packages. Journal of Food Science, 61(5), 956-961.

[2] Fonseca, S., Oliviera, F., Lino, I., Brecht, J., \& Chau, K. (2000, January). Modeling O2 and $\mathrm{CO} 2$ exchange for development of perforation mediated modified atmosphere packaging. Journal of Food Engineering, 43(1), 9-15.

[3] Paul, D., \& Clark, R. (2002, October 1). Modeling of Modified Atmosphere Packaging based on designs with a Membrane and Perforations. Journal on Membrane Science, 208(1-2), 269-283.

[4] Sanz, C., Perez, A., Olias, R., \& Olias, J. (1999, July - August). Quality of Strawberries Packed with Perforated Polypropylene. Journal of Food Science, 29(4), 748-752.

[5] Gonzales, J., Ferrer, A., Oria, R., \& Salvador, M. (2008, May). Determination of $\mathrm{O} 2$ and $\mathrm{CO} 2$ transmission rate through microperforated films for modified atmosphere packaging of fresh fruits and vegetables. Journal of Food Engineering, 86(2), 194-201.

[6] Oliviera, F., Fonseca, S., Oliviera, J., Brecht, J., \& Chau, K. (1998, October ). Development of Perforation - Mediated Modified Atmosphere Packaging to Preserve Fresh Fruit and Vegetable Quality After Harvest. Food Science and Technology International, 4(5), 339 352.
[7] Ozdemir, I., Monnet, F., \& Gouble, B. (2005, May). Simple Determination of the $\mathrm{O} 2$ and $\mathrm{CO} 2$ Permeances of Microperforated Pouches for Modified Atmosphere Packaging of Respiring Foods. Postharvest Biology and Technology, 36(2), 209-213.

[8] Silva, F., Chau, K., Brecht, J., \& Sargent, S. (1999). Tubes for Modified Atmosphere Packaging of Fresh Fruits and Vegetables. Applied Engineering in Agriculture, 15(4), 313-318.

[9] Kader, A. A., Zagory, D., \& Kerbel, E. (1989). Modified Atmosphere Packaging of Fruits and Vegetables. Critical Reviews in Food Science and Nutrition, 28(1), 1-30.

[10] Beaudry, R., Cameron, C., Shirazi, A., \& Dostal-Lange, D. (1992, May). ModifiedAtmosphere Packaging of Blueberry Fruit - Effect of Temperature on Package $\mathrm{O} 2$ \& CO2. Journal of the American Society for Horticultural Science, 117(3), 436-441.

[11] Exama, A., Arul, J., Lencki, R., Lee, L., \& Toupin, C. (1993, NOV-DEC). Suitability of Plastic Films for Modified Atmosphere Packaging of Fruits and Vegetables. Journal OF Food Science, 58(6), 1365-1370.

[12] Cameron, A., Boylanpett, W., \& Lee, J. (1989, NOV - DEC). Design of Modified Atmosphere Packaging Systems Modeling Oxygen Concentrations Within Sealed Packages of Tomato Fruits. Journal of Food Science, 54(6), 14131416. 
[13] Amanatidou, A., Slump, R., Gorris, L., \& Smid, E. (2000, Jan-Feb). High Oxygen and High Carbon Dioxide Modified Atmosphere for Shelf - life Extension of Minimally Processed Carrots. Journal of Food Science, 65(1), 61-66.

[14] Hertog, M., Peppelenbous, H., Evelo, R., \& Tijskens, L. (1998, Nov). A New Dynamic and Generic Model of Gas Exchange of Respiring Produce; the Effects of Oxygen, Carbon Dioxide and Temperature. Postharvest Biology and Technology, 14(3), 335-349

[15] Lee, D., Haggar, P., Lee, J., \& Yam, K. (1991, November). Model for Fresh Produce Respiration in Modified Atmospheres Based on Principles of Enzyme Kinetic. Journal of Food Science, 56(6), 1580-1585.

[16] Del-Valle, V.; Almenar, E.; HernándezMuñoz, P.; Lagarón, J.M.; Catalá, R.; Gavara, R.. Volatile Organic Compound Permeation Through Porous Polymeric Films for Modified Atmosphere Packaging of Foods. Journal of the Science of Food and Agriculture. 2004;84(9):937-942

[17] Emond, J., Castaigne, F., Toupin, C., \& Desilets, D. (1991, February). Mathematical Modeling of Gas Exchange in Modified Atmosphere Packaging. Transactions of the ASAE, 34(1), 239245.

[18] Fonseca, S., Oliviera, F., Lino, I., Brecht, J., \& Chau, K. (2000, January). Modeling $\mathrm{O} 2$ and CO2 Exchange for Development of Perforation Mediated Modified Atmosphere Packaging. Journal of Food Engineering, 43(1), 9-15.
[19] Fishman, S., Rodov, V., \& Ben Yehoshua, S. (1996, September - October). Mathematical Model for Perforation Effect on Oxygen and Water Vapor Dynamics in Modified Atmosphere Packages. Journal of Food Science, 61(5), 956-961.

[20] Min-Ji Kwon, Yun Hee Jo, Duck Soon An, and Dong Sun Lee (2013). Applicability of Simplified Simulation Models for Perforation-Mediated Modified Atmosphere Packaging of Fresh Produce. Mathematical Problems in Engineering, Volume 2013, Article ID 267629, 9 pages. [LINK]

[21] Techavises, N., and Yoshio, H. (2008, March). Development of a Mathematical Model for Simulating Gas and Water Vapor Exchanges in Modified Atmosphere Packaging with Macroscopic Perforations. Journal of Food Engineering, 85 (1), 94 - 104.

[22] Renault. P., S. M. (1994a). Gas Exchange in Modified Atmosphere Packaging. I; A New Theoretical Approach for Microperforated Packs. International Journal of Food Science Technology, 29, 365-378. Hirata, T., Makino, Y., Ishikawa, Y., Katsuura, S., \& Hasegawa, Y. (1996, July - August). Theoretical Model for Designing Modified Atmosphere Packaging with a Perforation. Transactions of the ASAE, 39(4), 14991504.

[24] Del-Valle, V.; Almenar, E.; Lagarón, J.M.; Catalá, R.; Gavara, R. Modelling Permeation Through Porous Polymeric Films for Modified Atmosphere Packaging. Food Additives and Contaminants. 2003;20(2):170-179. 
[25] Rennie, T., \& Tavoularis, S. (2009, January). Perforation-mediated Modified Atmosphere Packaging Part I. Development of a Mathematical Model. Postharvest Biology and Technology, 51(1), 1-9.

[26] Emond, J., Chau, K., Brecht, J., \& Ngadi, M. (1998). Mathematical Modeling of Gas Concentration Profiles In Modified Atmosphere Bulk Packages. Transactions of the ASAE, 41(4), 1075-1082.

[27] ASTM D 3985. (n.d.). Standard Test Method for Oxygen Gas Transmission Rate Through Plastic Film and Sheeting Using a Coulometric Sensor.

[28] Ghosh, V., \& Anantheswaran, R. C. (2001). Oxygen Transmission Rate through Micro-perforated Films; Measurement and Model Comparison. Journal of Food Process Engineering, 113-133.

[29] Gonzalez, J., Ferrer, A., Oria, R., \& Salvador, M. (2013, November). Alternative Method for Determining $\mathrm{O} 2$ and $\mathrm{CO} 2$ Transmission Rates Through Microperforated Films for Modified Atmosphere Packs. Packaging Technology and Science, 26(7), 413-421.

[30] Moyls, L., Hocking, R., Beveridge, T., \& Timber, G. (1992). Exponential Decay Method for Determining Gas Transmission Rate for Films. Transactions of the ASAE, 1259-1265.
[31] Abdellatief, A., \& Welt, B. A. (2012). Comparison of New Dynamic Accumulation Method for Measuring Oxygen Transmission Rate of Packaging Against the Steady-State Method Described by ASTM D3985. Packaging Technology and Science, DOI: 10.1002/ pts. 1974.

[32] Crank, J. (1975). The Mathematics of Diffusion (2nd ed.). Oxford, England: Clarendon Press.

[33] Meidner, H., \& Mansfield, T. (1968). Physiology of Stomata. Maidenhead, Berkshire, England: McGraw-Hill Publishing Company Limited. [34] Crank, J., \& Nicolson, P. (1947). A Practical Method for Numerical Evaluation of Solutions of Partial Differential Equations of the Heat Conduction Type. Proceeding of the Cambridge Philosophical Society, 43(1), 50-67.

Fuller, D. P., Schettler, P. D., and Giddings, J. C. (1966, May). A New Method For Prediction of Binary Gas Phase Diffusion Coefficients. Industrial and Engineering Chemistry, 58 (5), 18 $-27$. 